\title{
OIL QUANTITY ANALYSIS OF LAVENDULA OFFICINALIS CHAIX. GROWN ACROSS ASHMIR VALLEY
}

\author{
Farah Shamas* and Suchi Modi \\ Department of Botany, School of Biological Sciences \\ Rabindranath Tagore University, Madhya Pradesh, India
}

\begin{abstract}
Essential oils (EOs) are volatile, natural, complex compounds characterized by a strong odour and are formed by aromatic plants as secondary metabolites. The essential oil of Lavendula officinalis was extracted using hydrodistillation process. Hydro-Distillation is potentially a very useful method to extract essential oil from various plants and from their different parts. The principle of extraction is based on the isotropic distillation. The yield is dependent on various parameters like weight of raw material, volume of water, size of raw material and nature of raw material. Samples from aerial parts of three Lavendula ecotypes were analyzed for essential oil content to find out as to which ecotype excels in oil content and which ecotype gave the minimum essential oil output. Air dried leafy stalks and stems of L. officinalis were taken and submitted to Hydro distillation for 4 hrs using Clevenger type apparatus. Briefly, the samples were immersed in water and heated to boiling, after which the essential oil was evaporated together with water vapour and finally collected in a condenser. The distillates (EOs) were isolated and dried over anhydrous sodium sulphate. The oils were stored in the sealed vials at $2^{\circ} \mathrm{C}$ for further studies. Each extraction was performed at least three times. The oil content was determined on an oil volume to tissue weight basis.
\end{abstract}

Estimated oil content was lowest in Srinagar ecotype to a highest in Pulwama ecotype. Pulwama ecotype was followed by Budgam ecotype. This could be due to the variation in altitude and location.

Keywords: Bacteria, Fungi, Contaminants, Tissue-culture.

\section{INTRODUCTION}

Nearly all cultures from ancient times have used plants as a source of medicine. In many developing countries traditional medicine is still the mainstay of healthcare and most of the drugs and cures usedcome from plants. In developed countries too, people are turning to herbal remedies. Besides, modern scientific medicine still depends on plants, and the knowledge gained from them, for some essential drugs. People in India and China are known to have used plants for healthcare for over 5,000 years (Petrovska, 2012). The role of medicinal plants is particularly important in Himalayan regions. These areas are richly endowed with a variety of plant species, many of which have medicinal properties. A large proportion of rural population in these areas depend on locally available plants to meet their health care requirements. The Valley of Kashmir being a reservoir of rich biodiversity has been using many plants and plant products in ameliorating various disorders. More than 50 percent of the plant species described in British Pharmacopeia is reported to grow in Kashmir Valley. Kashmir region is rich in medicinal plants and the studies of ecotypes have been carried out by various researchers (Mushtaq and Modi, 2019). Literature indicates that 572 plant species belonging to 109 different families have medicinal value (J\&K Forest Department, 2020). Over the past few years, the medicinal plants have regained a wide recognition due to an escalating faith in herbal medicine in view of its lesser side effects compared to allopathic medicines and the necessity of meeting the requirements of medicines for an increasing human population. 
The Lamiaceae family consists of 236 genera. A wellknown member of this family, the genus Lavandula comprises 39 species, 30 subspecies and varieties as well as 17 hybrid taxa (Blažeković, B. et al., 2018). It is native to southern Europe and the Mediterranean area and is commercially cultivated in France, Spain, Portugal, Hungary, the UK, Bulgaria, Australia, China, India and the USA (Verma et al, 2010). Chromosome counts in $L$. angustifolia vary considerably in the literature with $2 \mathrm{n}$ (diploid) estimates ranging between 36 and 75, (Urwin et al., 2007). The consensus is around $2 \mathrm{n}=50$ for the species and hybrids thereof. Chromosome number estimates suggest that the species is ancient polyploid (Upson and Andrews, 2004). Natural polyploidy is present within the Lamiaceae, for example within Thymus (Lopez-Pujol et al., 2004), Glechoma (Widen and Widen, 2000) and Lavandula (Upson and Andrews, 2004). The chromosome size in species of Lavandula is relatively small, so although the genome size is unknown it is likely to be small. Many members of the Lavendula genus are cultivated extensively in temperate climates grown mainly for their essential oils. All the Lavandula taxa are highly aromatic plants due to the presence of a complex mixture of essential oil produced in the glandular trichomes on the surface of their flowers and leaves (Blažeković et al., 2012; Blažeković et al., 2018) which are used in perfumery, cosmetics, food processing and nowadays also in 'aromatherapy' products. However, only three taxa, $L$. angustifolia Mill. (lavender), L. latifolia Medik. (spike lavender) and their hybrid L. X intermedia (lavandin), are commercially important and widely grown for essential oil production (Woronuk et al., 2011; Kıvrak, 2018). Lavendula is regarded as 'crown' in the world of aroma. The dried flowers have also been used from time immemorial in pillows, sachets etc. for promoting sleep and relaxation. Numerous lavender plants are also sold as ornamental plants for the garden; these include L. latifolia, $L$. pinnata, $L$. lanata, $L$. dentateand $L$. stoechas and their numerous cultivars.

Lavendula officinalis Chaix (syn. Lavendula spica, Lavendula vera, Lavendula angustifolia) commonly known as English lavender, common lavender, true lavender is found in continents North America, Europe and Australia (Schutte, 2008). The main growing countries are Bulgaria and France and on smaller areas in Morocco, the former republics of Yugoslavia, Hungary, Italia, Russia, Spain, Romania, Ukraine, Turkey, and others (Zheljazkov, 2012; Jianu et al., 2013). It grows at a latitude of 30-40 degrees north, at an altitude of $3000 \mathrm{ft}$. It requires hot, dry and sunny climate and grows best in an alkaline soil with a $\mathrm{pH}$ of 6.4 to 8.2. The Lamiaceae plant family has been described to be rich in essential oil (Adorjan and
Buchbauer, 2010). Essential oils are plant-based volatile oils with strong aromatic components that could be biosynthesized in different plant organs as secondary metabolites (Khan and Dwivedi, 2018). They are complex mixtures of volatile compounds such as terpenes (mostly monoterpenes and sesquiterpenes), phenolics and alcohols (Lucchesi et al., 2004). Lavender is one of the most commonly grown plants rich in essential oils used in the pharmaceutical, food and cosmetic industries (Kara and Baydar, 2013).

\section{MATERIALS AND METHODOLOGY}

\section{Collection of plant material}

Leaves and stems of Lavendula officinalis Chaix. were collected at full flowering stage in the month of June-July from natural populations at three different locations of Kashmir region. First collection was from the city of Srinagar, another was from district Budgam and the third was from Bonera, district Pulwama. The collection was done by simple random process. Fresh plant material was taken and then washed with distilled water to remove dust and other impurities. The plant material was dried in the shade for preparation of plant extract.

\section{Essential oil extraction and Quantity analysis}

Essential oil content was estimated by the method devised by Agranosa et al. (1998). Leaves and stems of the plant (Lavendula officinalis Chaix.) were used for estimation of essential oil content.

The raw material (dried stems or leafy stalks) was pounded in a mortar immediately prior to isolation of essential oils. Next, weighed sample of plant material (20 g) was placed in a $1000 \mathrm{~mL}$ round-bottomed flask, immersed in $400 \mathrm{~mL}$ distilled water and submitted to Hydro distillation for 4 hrs using Clevenger type apparatus. Briefly, the samples were immersed in water and heated to boiling, after which the essential oil was evaporated together with water vapour and finally collected in a condenser. The distillates (EOs) were isolated and dried over anhydrous sodium sulphate. The oils were stored in the sealed vials at $2^{\circ} \mathrm{C}$ for further studies. Each extraction was performed at least three times. The oil content was determined on an oil volume to tissue weight basis.

The formula used for calculating oil per centage is: $\mathrm{Y} / \mathrm{X}$ $\times 100$

where,

Weight of sample used $=\mathrm{X}$

Number of units of oil $=\mathrm{Y}$

Value of 1 unit $\quad=0.1 \mathrm{ml}$

Amount of oil $\quad=\mathrm{Y} \times 0.1 \mathrm{ml}=0 . \mathrm{Y} \mathrm{ml}$ 


\section{RESULTS}

Samples from aerial parts of three Lavendula ecotypes were analyzed for essential oil content to find out as to which ecotype excels in oil content and which ecotype gave the maximum essential oil output. Estimated oil content for three ecotypes ranged from a lowest (2.65 per cent) in Srinagar ecotype to a highest (4.63 per cent) in Pulwama ecotype. Pulwama ecotype was followed by Budgam (3.32 per cent), Srinagar (2.65 per cent). Srinagar ecotype had the lowest oil content among all ecotypes.

\section{DISCUSSION AND CONCLUSION}

On the basis of the present investigation, it could be concluded that Lavandula angustifolia plant is rich in essential oils. Jainu et al. used the methods of Craveiro et al., 1976 and isolated 22 components which were identified in the EO obtained from L. angustifolia Miller, representing $99.9 \%$ of the total, the major components being caryophyllene $24.12 \%$, beta-phellandrene $16 \%$ and eucalyptol (1,8-cineol) $15.69 \%$. The EO of Lavandula $\times$ intermedia has as major component camphor $32.7 \%$ and eucalyptol 26.9\%, 24 components being identified in this case representing $98.26 \%$ of the total. Similar studies were carried out by Abroomand et al., Bouzouita, et al., De Martino et al., and Imelouane. All the results suggest the potential oil content in Lavandula species.

\section{REFERENCES}

1. Petrovska B. B. (2012). Historical review of medicinal plants' usage. Pharmacognosy reviews, 6 (11), 1-5. https://doi.org/10.4103/0973-7847.95849.

2. J\&K Forest Department, 2020; Geographical Features of Jammu and Kashmir, available at http://jkforest.gov.in/geo_area.html\# visited on 25 August, 2020.

3. Blažeković, B., Yang, W., Wang, Y., Li, C., Kindl, M., Pepeljnjak, S., \& Vladimir-Knežević, S. (2018). Composition, antimicrobial and antioxidant activities of essential oils of Lavandula X intermedia 'Budrovka' and L. angustifolia cultivated in Croatia. Industrial crops and products, 123, 173-182.

4. Verma, R. S., Rahman, L. U., Chanotiya, C. S., Verma, R. K., Chauhan, A., Yadav, A., ... \& Yadav, A. K. (2010). Essential oil composition of Lavandula augustifolia Mill. cultivated in the mid hills of Uttarakhand, India. Journal of the serbian chemical society, 75(3), 343-348.

5. Urwin, N. A., Horsnell, J., \& Moon, T. (2007). Generation and characterisation of colchicine- induced autotetraploid Lavandula angustifolia. Euphytica, 156(1-2), 257-266.

6. Upson, T., \& Andrews, S. (2004). Genus Lavandula (Botanical Magazine Monograph. Andrews-//Royal Botanic Gardens, Kew, GB.

7. López ujol, J. O. R. D. I., Bosch, M., Simon, J., \& Blanché, C. (2004). Allozyme diversity in the tetraploid endemic Thymus loscosii (Lamiaceae). Annals of Botany, 93(3), 323-332.

8. Widén, B., \& Widén, M. (2000). Enzyme variation and inheritance in Glechoma hederacea (Lamiaceae), a diploidized tetraploid. Hereditas, 132(3), 229-241.

9. Blažeković, B., Stabentheiner, E., Brantner, A., \& Vladimir-Knežević, S. (2012). A comparative study on glandular trichomes of Lavandula X intermedia 'Budrovka' and L. angustifolia. Phyton, 52(2), 227244.

10. Woronuk, G., Demissie, Z., Rheault, M., \& Mahmoud, S. (2011). Biosynthesis and therapeutic properties of Lavandula essential oil constituents. Planta medica, 77(01), 7-15.

11. Kıvrak, Ş. (2018). Essential oil composition and antioxidant activities of eight cultivars of Lavender and Lavandin from western Anatolia. Industrial Crops and Products, 117, 88-96.

12. Schutte, A. (2008). Lavandula angustifolia-New Crop Summary \& Recommendations, Hort 5051 May 5, 2008.

13. Zheljazkov, V. D., Astatkie, T., \& Hristov, A. N. (2012). Lavender and hyssop productivity, oil content, and bioactivity as a function of harvest time and drying. Industrial Crops and Products, 36(1), 222228.

14. Jianu, C., Pop, G., T Gruia, A., \& Horhat, F. G. (2013). Chemical composition and antimicrobial activity of essential oils of lavender (Lavandula angustifolia) and lavandin (Lavandula X intermedia) grown in Western Romania. International journal of agriculture and biology, 15(4), 772-776.

15. Adorjan, B., \& Buchbauer, G. (2010). Biological properties of essential oils: an updated review. Flavour and Fragrance Journal, 25(6), 407-426.

16. Khan, M. F., \& Dwivedi, A. K. (2018). A Review on Techniques Available for the Extraction of Essential Oils from Various Plants. International Research Journal of Engineering and Technology, 5(5), 5-8.

17. Lucchesi, M. E., Chemat, F., \& Smadja, J. (2004). Solvent-free microwave extraction of essential oil 
from aromatic herbs: comparison with conventional hydro-distillation. Journal of Chromatography $a$, 1043(2), 323-327.

18. Kara, N., \& Baydar, H. (2013). Determination of lavender and lavandin cultivars (Lavandula sp.) containing high quality essential oil in Isparta, Turkey. Turk J Field Crops, 18(1), 58-65.
19. Mushtaq, N. U., \& Modi, S. (2019). Cultivation and Morphological Characterization of different Ecotypes of Kala Zeera (Bunium persicum Boiss.) Across Kashmir Valley. International Journal of Basic and Applied Biology, 6(2), 72-74. p-ISSN: 2349-5820, eISSN: 2349-5839. 